\title{
2 Flunarazine in Opthalmic Migraine
}

Dr Sanjoy Chowdhury*, Dr Madhumita Srivastava, Dr Nilanjan.

*MS. DO. DNB. DSc (Hon.), Director (Medical and Health Services) SAIL/BGH, Head Eye Dept.Bokaro Steel City, Jharkhand, India.email:drsanjoy@hotmail.com

\section{Abstract}

About one in ten people suffer from attacks of migraine around the world, still, it is one of the most misconceived, misdiagnosed and inadequately treated headaches. Flunarizine can stabilize blood vessels by blocking calcium channels. Hence it is used in the treatment of migraine with limited success.

AIM: Flunarizine was used in all cases of ophthalmoplegic migraine at our centre to evaluate its clinical efficacy. At least 200 cases of migraine were followed up over a period of two years to find out Ophthalmoplegia with the help of standardized questionnaire.

Result: Of the total 200 migraineurs, 10 patients had oculomotor dysfunction (Opthalmoplegic Migraine). It appears clear from this study that migraine can cause episodic pupillary abnormalities through different mechanisms. Flunarizine can be administered safely and effectively in these cases.

Key Words: Ophthalmoplegic migraine, Flunarazine, Headache

\section{Introduction}

The term "migraine" is applied for various headache syndromes and to the neurologic phenomenon. According to 'International Headache Society' Ophthalmoplegic migraine is included in the classification of migraine (Table-1). It is a very rare clinical entity, hence often goes unnoticed and unreported. A diagnosis of migraine is clinical and based on several aspects of the patient's history, it sometimes becomes confusing. In Ophthalmoplegic migraine, ocular findings become an important diagnostic feature in the form of oculomotor dysfunction ranging from episodic mydriasis to total third nerve paralysis, many times considered by its reappearance. Most physicians view unilateral pupillary dilatation especially when accompanied by headache, as an ominous sign, but the neurovascular response in the migraineurs can give rise to this episodic ophthalmoplegic signs. ${ }^{[1,2]}$ 
The Researchers' - Volume VI, Issue I, 20 March-2020

International Research Journal (Double-blind peer-reviewed)

Date of Acceptance : 12 November 2019
ISSN : 2455-1503

Impact Factor - 3.635

DOI - 10.21276/tr.2020.6.1.AN2

\section{(C) Dr Sanjoy Chowdhury, Dr Madhumita Srivastava, Dr Nilanjan.}

About one among ten people around the world suffer from attacks of migraine, yet it is one of the most misunderstood, misdiagnosed and inappropriately treated headaches. The growing volume of researches show that migraine is caused by a rapid widening and narrowing of blood vessel walls in the brain, which causes irritation in its walls. The whole phenomenon is orchestrated by a chemical messenger (neurotransmitter) called serotonin in the brain. This chemical is supposed to link the nerve cells and help the blood vessels constrict and reduce the feeling of pain. When a migraine is in the offing, serotonin level falls down and blood vessels remain contracted. The constricted arteries incite premonitory phenomenon like visual distortion. Flunarizine can stabilize blood vessels by blocking calcium channels. Hence it is used in the treatment of migraine with limited success. ${ }^{[3]}$ In a Prospective study, flunarizine was used in all cases of ophthalmoplegic migraine at our centre to evaluate its clinical efficacy.

\section{Materials and Methods}

200 cases of migraine were followed up over a period of two years to find out Ophthalmoplegia. A standardized questionnaire (Table-2), based on existing International Headache Society diagnostic criteria was distributed consecutively to the patients/or parents of patients presenting at the eye Clinic of Bokaro General Hospital for diagnosis of migraine over a period of two years.

\section{Diagnostic Criteria for Migraine}

The criteria for diagnosis of migraine in this study were a history of headache and any two or more or the following symptoms:

1) Sudden headaches separated by symptom-free intervals.

2) Hemi crania.

3) Abdominal pain \& nausea or vomiting associated with headache.

4) Throbbing headache.

5) Complete relief after a period of rest.

6) An aura or "strange sensations" prior to or during headache and

7) A family history of migraine. 
The Researchers' - Volume VI, Issue I, 20 March-2020

International Research Journal (Double-blind peer-reviewed)

Date of Acceptance : 12 November 2019
ISSN : 2455-1503

Impact Factor - 3.635

DOI - 10.21276/tr.2020.6.1.AN2

(C) Dr Sanjoy Chowdhury, Dr Madhumita Srivastava, Dr Nilanjan.

The participants were also polled on several "para migrainous" symptoms, such as motion sickness, visual whiteouts, seizures and sleep disturbances. These symptoms were not considered diagnostic for migraine but have been frequently reported in association with migraine. 2200 questionnaires were distributed during 2015-2016 with a 95 per cent completion rate.

At least 218 patients were found to be suffering from migraine. Out of this, 18 patients were lost in the follow-up and 200 were followed up for 2 years to find out the incidence of Ophthalmoplegia. Each of the Ophthalmoplegic patients were subjected again to detailed history, clinical and neuro-ophthalmological examination which included visual fields, colour vision, ocular motility and included visual fields, colour vision, ocular motility and fundus examination.

Accommodation (near point of blur) was measured on "RAF Rule". Pupillary size and reaction to light and near, response to pilocarpine $1 \%$ and presence of any conjunctival blanching were also noted. Their clinical features were summarized in Table-3.

Based on these clinical presentations, they were divided into two groups

1. Pupillary Group : : Mydriasis only.

2. Ophthalmoplegic Group : Total 3rd nerve palsy.

Besides routine investigations, CT scan with plain and contrast enhanced were done in all cases; seven patients had undergone MR-Angiography.

All the patients with Oculomotor dysfunction were treated with Flunarizine (5 or 10mg) for a maximum period of three months. Age and sex matched migraineurs without oculomotor dysfunctions were taken as control.

\section{Results}

Mean age of the target population was 2 years and that of migraineurs were 18 years, where as it was 17 years in cases with Opthalmoplegic Migraine. Of the total 200 migraineurs, 10 patients 
The Researchers' - Volume VI, Issue I, 20 March-2020

International Research Journal (Double-blind peer-reviewed)

Date of Acceptance : 12 November 2019
ISSN : 2455-1503

Impact Factor $\mathbf{-} 3.635$

DOI - 10.21276/tr.2020.6.1.AN2

(C) Dr Sanjoy Chowdhury, Dr Madhumita Srivastava, Dr Nilanjan.

had oculomotor dysfunction (Opthalmoplegic Migraine). Among them eight patients had recurrent unilateral mydriasis and included in the pupillary group. Two patients had alternating third nerve paralysis and classified in ophthalmoplegic group. Their clinical features are described in Table-3. Four patients in pupillary group and both of ophthalmoplegic group had shown favourable response to Flunarizine. Reduced headache, reduced para migrainous symptoms along with early recovery of oculomotor dysfunction were noticed with this treatment. Whereas improvement was noticed in four cases of the non-ophthalmoplegic migraineurs (age and sex matched controls). The difference was however, not statistically significant $(\mathrm{P}>0.05)$.

\section{Discussion}

Recurrent transient mydriasis without extra ocular involvement has not to my knowledge, been reported in any case of intracranial space occupying lesion or diabetes. A patient with an acute attack of headache and mydriasis presents a more difficult problem. Different reports have shown that isolated mydriasis is seldom the result of intracranial space occupying lesion. There is a $10 \%$ prevalence of migraine in the target population in our study among which $5 \%$ oculomotor dysfunction. This was slightly less than other reports. ${ }^{[4]}$ Oculomotor has been reported sporadically by different authors, ${ }^{[4]}$ all from West. Through rare, Opthalmoplegic migraine has become a well recognized clinical entity characterised by history of migraine, ophthalmoplegia and exclusion of other causes. None of the migraineurs with oculomotor dysfunction in this study had any pathological lesion (as ruled out by MR- angiography) which could attribute to the disease entity.

Hypothetically, this may be a manifestation of compressive (direct) or ischemic (due to pressure vasa nervorum) oculomotor 'neuropathy. ${ }^{[4]}$ The pupillary dilatation which occurred in the migraineurs may imply involvement of the ciliary ganglion circulate in the migrainous process and nas previously been reported in the literature. ${ }^{[5,6,7]}$

Migraine rarely responds to common analgesics. Most of the antimigraine drugs like ergotamine are designed to increase the level of serotonin. The latest medicines in the arsenal of a 
The Researchers' - Volume VI, Issue I, 20 March-2020

International Research Journal (Double-blind peer-reviewed)

Date of Acceptance : 12 November 2019
ISSN : 2455-1503

Impact Factor - 3.635

DOI - 10.21276/tr.2020.6.1.AN2

(C) Dr Sanjoy Chowdhury, Dr Madhumita Srivastava, Dr Nilanjan.

neurologist are the 'triptans' which act as nemesis of serotonin. These drugs cannot be used as prophylactic or for a long term treatment.

In this study, Flunarizine was id to be effective in reducing the number and severity of migraine attack in around $40 \%$ cases of migraineurs and $60 \%$ cases of ophthalmoplegic migraine. This acts by blocking calcium channels probably in the microvasculature of oculomotor nerve.

\section{Conclusion}

It appears clear from this study that migraine can cause episodic pupillary abnormalities through different mechanisms. It also highlights that pupillary dilatation accompanied by headache is not always an ominous sign and could be migrainous in origin. Flunarizine can be administered safely and effectively in these cases.

\section{References}

1) Stephen DS, Lipton R. B. Overview of diagnosis and treatment of migraine. Neurology 44 (Suppl. 7), 1994, S6- S16.

2) Mark W. Weatheral. The diagnosis and treatment of chronic migraine. The Adv Chronic Dis. 2015 May; 6(3): 115-123.

3) Woods D, O'connor PS, Fleming R. Episodic unilateral mydriasis and migraine. Am J Ophthalmol 98, 1984: 229- 234

4) Stang PE Yanagihara T, Swanson JW, et al. Incidence of migraine headache: a population based study in Olmsted County, Minnesota. Neurology, 1992:42:1657-62.

5) Miler NR, Keltner JL et al. Intermittent pupillary dilatation in a young woman. Surv Opthalmol, 1986; 31: 65-68.

6) Chowdhury S. Episodic Opthalmoplegia in migraine. Indian Opthalmology year book 1998 ed JK Pasricha. 321-324.

7) Stephen D. Silberstein. Preventive Migraine Treatment. Continuum (Minneap Minn). 2015 Aug; 21(4 Headache): 973-989. 
The Researchers' - Volume VI, Issue I, 20 March-2020

International Research Journal (Double-blind peer-reviewed)

Date of Acceptance : 12 November 2019
ISSN : 2455-1503

Impact Factor - 3.635

DOI - 10.21276/tr.2020.6.1.AN2

(C) Dr Sanjoy Chowdhury, Dr Madhumita Srivastava, Dr Nilanjan.

Table: 1 CLASSIFICATION OF MIGRAINE (BY INTERNATIONAL SOCIETY)

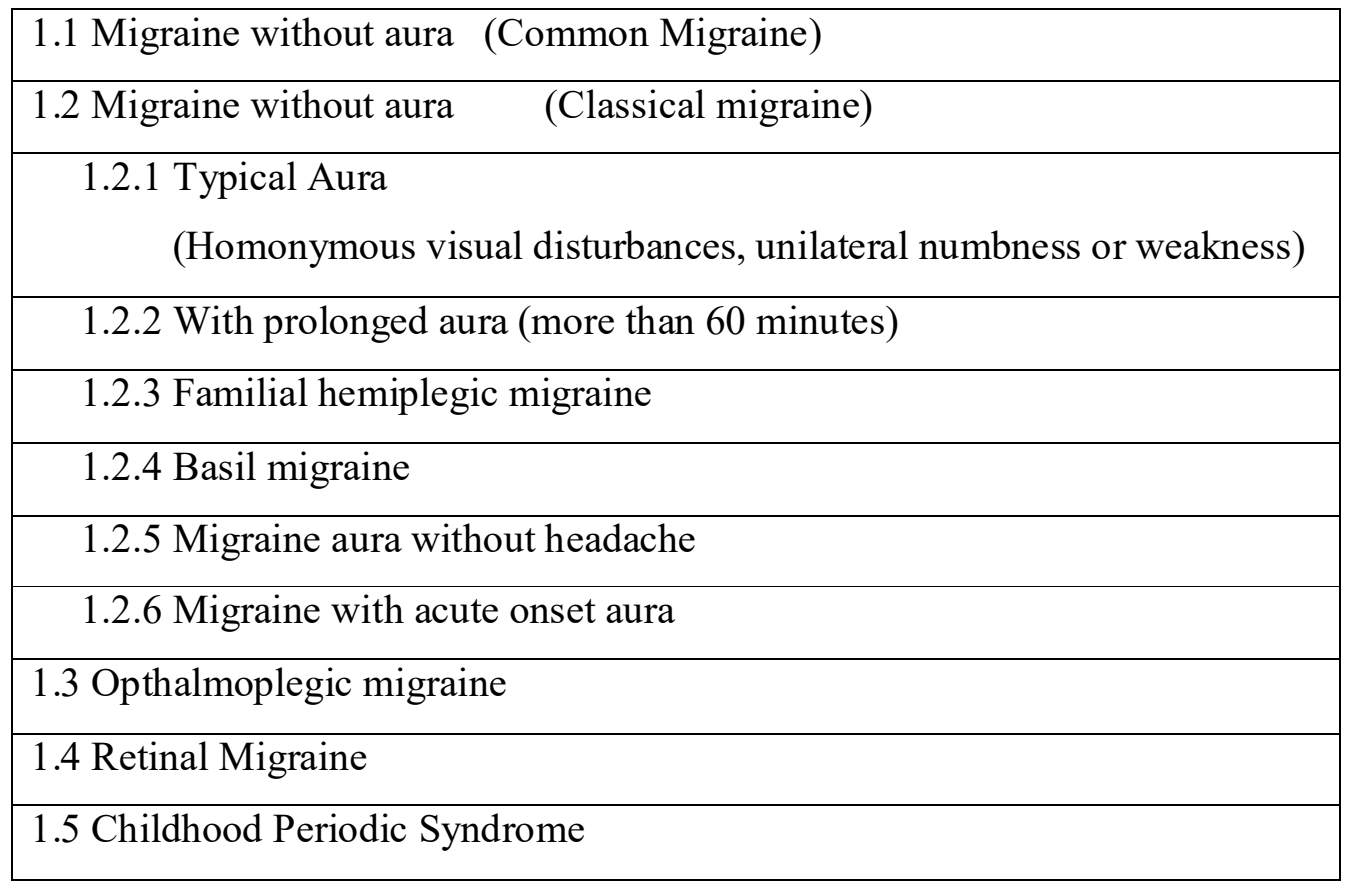


Table: 2 SUMMARIES OF CLINICAL DATA

\begin{tabular}{|c|c|c|}
\hline Clinical Data & Pupillary group & Opthalmoplegic group \\
\hline Number & 8 & 2 \\
\hline Male ; Female & $3: 5$ & $1: 1$ \\
\hline Mean age & $16.6(8-27)$ & $18(12-24)$ \\
\hline Presenting Feature & $\begin{array}{c}\text { Headache, Blurred } \\
\text { vision }\end{array}$ & $\begin{array}{c}\text { Dropping of eyelids } \\
\text { Headache }\end{array}$ \\
\hline Number of attack & $1-2$ year & $\begin{array}{c}\text { Case } 1: 2 / \text { years, Case } \\
2: 2\end{array}$ \\
\hline Duration of attack & 30 minutes -2 days & $1-5$ weeks \\
\hline Accommodation & Normal (except one) & Normal \\
\hline History of Migraine & $\begin{array}{c}\text { Yes } \\
\text { (Classic: } 6 \text {, Common } \\
: 2)\end{array}$ & $\begin{array}{c}\text { Yes } \\
\text { (Classic: } 1 \text {, Common } \\
: 1)\end{array}$ \\
\hline Pupillary difference & $2-3 \mathrm{~mm}$ & $2-3 \mathrm{~mm}$ \\
\hline $\begin{array}{l}\text { Reaction to light and } \\
\text { near } \\
\text { (difference in two eyes) }\end{array}$ & & \\
\hline Ptosis/ third nerve palsy & None & $\begin{array}{c}\text { Case - 1: Occasional } \\
\text { Case -2: Two attacks } \\
\text { (alternating) }\end{array}$ \\
\hline $\begin{array}{l}\text { Response to Pilocarpine } \\
1 \%\end{array}$ & $\begin{array}{c}\text { Normal } \\
\text { (Tested in four cases) }\end{array}$ & Normal \\
\hline CT/MR Angiography & Normal & Normal \\
\hline
\end{tabular}


The Researchers' - Volume VI, Issue I, 20 March-2020

International Research Journal (Double-blind peer-reviewed)

Date of Acceptance : 12 November 2019

(C) Dr Sanjoy Chowdhury, Dr Madhumita Srivastava, Dr Nilanjan.
ISSN : 2455-1503

Impact Factor - 3.635

DOI - 10.21276/tr.2020.6.1.AN2

Table 3: QUESTIONNARE FOR DIGNOSIS OF MIGRAINE

\begin{tabular}{|l|l|}
\hline Name \\
\hline Mark this if first visit Male \\
\hline Education \\
\hline General health
\end{tabular}

